\title{
Preparedness of Interns for Hospital Practice before and after an Orientation Programme
}

\section{Zayapragassarazan $\mathbf{Z}^{1}$}

'Department of Medical Education, Jawaharlal Institute of Postgraduate Medical Education and Research (JIPMER) Puducherry, India

Email:zprazan@yahoo.co.in Tel: 9894846929

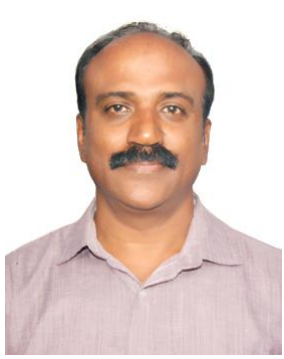

\begin{abstract}
Appropriately designed educational programmes would help medical students gain confidence and mitigate fears of internship. The aim of this pilot study is to compare the preparedness of interns for hospital practice before and after attending a two-day "Interns Orientation Programme". A small batch of interns in a tertiary care teaching hospital were administered with "Interns Preparedness for Hospital Practice" questionnaire before and after a two-day orientation programme and the results were compared. The difference in the mean scores of the preparedness for hospital practice in the chosen areas of orientation programme among all the interns were found to be higher and hence the overall preparedness of the interns after the orientation programme was found to be higher which was statistically significant $(\mathrm{P}<0.001)$. Assessing the preparedness of interns will help the medical schools to develop necessary training strategies to prepare the interns mentally and professionally ready for hospital practice during their internship. Appropriate selection of content areas for preparing the interns and mode of training them is also essential before they take up their internship.
\end{abstract}

Keywords: Internship, Orientation programme, Interns preparedness, Self-reporting.

Citation | Zayapragassarazan Z (2017). Preparedness of Interns for Hospital Practice before and after an Orientation Programme. Asian Journal of Education and Training, 3(2): 105-109.

History:

Received: 18 October 2017

Revised: 10 November 2017

Accepted: 13 November 2017

Published: 16 November 2017

Licensed: This work is licensed under a Creative Commons Attribution 3.0 License (cc) IE

Publisher:Asian Online Journal Publishing Group
Contribution/Acknowledgement: The author would like to express his sincere thanks to JIPMER administration and Dr. Gitanjali B, Head of the Department of Medical Education, JIPMER for their support.

Funding: This study received no specific financial support.

Competing Interests: The author declares that there are no conflicts of interests regarding the publication of this paper.

Transparency: The author confirms that the manuscript is an honest, accurate, and transparent account of the study was reported; that no vital features of the study have been omitted; and that any discrepancies from the study as planned have been explained.

Ethical: This study follows all ethical practices during writing.

\section{Contents}

1. Introduction

2. Method

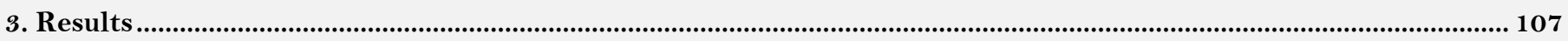

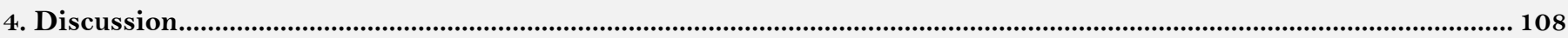

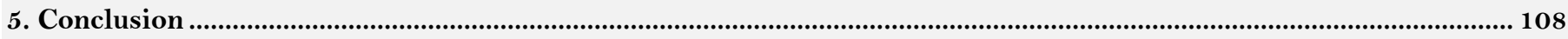

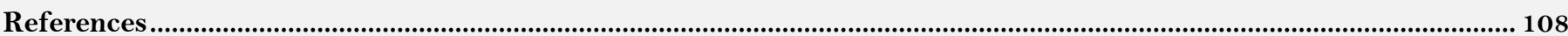




\section{Introduction}

Internship is a phase of training wherein a graduate is expected to conduct actual practice of medical and health care and acquire skills under supervision so that he/she may become capable of functioning independently. In India, the duration of the MBBS course extends over a period of four and a half academic years which are divided into four Professional years. After completion of the academic study, a candidate has to complete 12 months of compulsory rotating internship so as to be eligible for the award of the degree of Bachelor of Medicine and Bachelor of Surgery (MBBS) and for registering in the State Medical Council. The intern shall be entrusted with clinical responsibilities under direct supervision of senior medical officer. They shall not be working independently (Medical Council of India Regulations on Graduate Medical Education, 1997). Graduating from medical school is a special time of life and the internship programme is the very beginning of the process of transition from medical student to junior doctor (Guidelines on Remediation of Doctors in the Intern Year, 2012). Students entering into medical course with certain mindset and attitude, but the knowledge acquired in preclinical, para-clinical and clinical experiences may influence their exit behaviour (GRDIY, 2012; Scicluna et al., 2014; Gouda et al., 2016).

The Intern Year is an important formative year, which may present some unique challenges to doctors. These challenges may include having to adapt quickly to a busy working environment in a relatively short period of time, working as part of a multi-disciplinary clinical team, often under pressure, and dealing in a professional and empathetic way with patients who may have complex clinical and personal issues (Cave et al., 2009; McNeil et al., 2012).

Various factors affect the performance of interns in their workplace during their internship. These includes, poor organization, lack of knowledge, attitude and skills in clinical judgements, lack of insight, personal and interpersonal factors, adjustment problems, etc. (Gome et al., 2008; GRDIY, 2012). Hence, their preparedness to take up internship should not be taken for granted and preparing them to take up internship with confidence is very important which directly or indirectly will affect the patient care. This will also enable a smooth transition from their routine college life to professional life. Some of these challenges can be addressed through a comprehensive orientation programme before they start their internship.

Close supervisory arrangements and encouragement to raise concerns with their trainers at the earliest opportunity will also play a key role in ensuring a smooth transition throughout intern training (Brennan et al., 2010). There are only few studies that assessed the transition from medical student to intern and there is limited understanding of what measures are required to assist intern development (Berridge et al., 2007; Gome et al., 2008; Brennan et al., 2010). This pilot study was undertaken in a tertiary care teaching hospital to assess the effectiveness of an Interns Orientation Programme with reference to the preparedness of the interns for internship before and after attending the orientation programme.

\section{Method}

\subsection{Study Design: Cross-Sectional Descriptive Study}

Population: Interns of a tertiary care teaching hospital in Puducherry, South India.

Sample: Candidates who have completed their four and a half years of their academic study and eligible to undergo internship during July 2014 in the selected tertiary care teaching hospital formed the sample for the study.

Sampling: Convenient sampling was used for the study and all the interns of the academic period of this study were invited to take part in this study. The total number of interns for the July 2014 batch was 19. All the 19 interns who attended the orientation programme were taken as sample for the study with their consent.

\subsection{Programme}

A two-day orientation program was held in July 2014 for this small batch of interns in the tertiary care teaching hospital identified for this study. The programme started with the orientation on basic information about the institution and its functioning. The programme was structured in a way that it addressed the common areas that demands interns attention for delivering quality care to the patients. The sessions on Duties and Responsibilities of Interns, Oral Communication, Written Communication, Maintaining Patients' Records, Interns Diary, Patient Safety, Rational Diagnostics \& Therapy, Ethics, Professionalism, Medico-legal Aspects, Drug Promotion, Biomedical Waste Management were scheduled for the orientation programme and were handled by resource persons of various disciplines. The program used a combination of interactive lectures, small group sessions and individual and group activities to introduce students to the internship program and their work environments.

\subsection{Tool}

A self-assessment tool to assess the preparedness for internship was developed by the researchers. The face validity and content validity of the tool was evaluated by an expert panel during and after development to ensure that the respondents had a complete comprehension of the tool used in the study. The tool was constructed to evaluate the preparedness of interns using a quantitative 5 -point scale $(0=$ Definitely not prepared, $1=$ Not prepared, $2=$ Don't Know, $3=$ Prepared and 4= Definitely prepared). The total number of items in the tool were 12.

\subsection{Administration of the Tool}

The questionnaire was administered to the interns before the beginning of the programme and immediately after the end of the programme after obtaining their consent.

\subsection{Scoring of the Tool}

One can score a minimum of zero and a maximum of four for each item. The overall raw score of an individual can range from 0 to 48. The raw scores calculated for all the items were converted to percentage. At the discretion of the investigators, the scores equal to and less than $49 \%$ were considered as low, the scores between $50 \%$ to $70 \%$ were considered as average and the scores equal to and above $71 \%$ were considered as high with respect to 
preparedness for internship. The quantitative data obtained from the respondents was entered to Microsoft Office Excel 2007 and the descriptive statistics was calculated for the overall sample. Answers to open-ended questions were collated to list the additional topics for the orientation programme and other comments stated by the respondents.

\subsection{Research Limitation}

This study used only a small number of interns belonging to a small batch and it may not represent all interns in India. The cross sectional design of this study only provided information about the preparedness of interns for internship at the given point of time.

\section{Results}

$15(79 \%)$ of interns were male and $4(21 \%)$ were female. Analysis of the raw scores revealed that before commencement of the orientation programme on an average $6(32 \%)$ interns were not prepared about professionalism, medical-legal aspects and drug promotion, $3(16 \%)$ were not prepared about ethics, rational diagnostics and therapy and patient safety and $3(16 \%)$ were not prepared about their duties and responsibilities. An average of $5 \%$ of interns were not prepared about oral communication, written communication, maintaining patient's records and intern's diary. An average of $4(21 \%)$ interns were not in a positon to assess their preparedness before the commencement of the orientation programme. Again, after attending the orientation programme, $2(11 \%)$ interns were not in a position to assess their preparedness for internship (Table 1).

Table-1. Showing the number and percentage of interns response to the items in the internship preparedness questionnaire.

\begin{tabular}{|c|c|c|c|c|c|c|c|c|c|c|c|}
\hline \multirow[t]{2}{*}{$\begin{array}{l}\text { Sl. } \\
\text { No. }\end{array}$} & Session & \multicolumn{2}{|c|}{$\begin{array}{l}\text { Definitely } \\
\text { Prepared }\end{array}$} & \multicolumn{2}{|l|}{ Prepared } & \multicolumn{2}{|c|}{ Don't' Know } & \multicolumn{2}{|c|}{ Not Prepared } & \multicolumn{2}{|c|}{$\begin{array}{l}\text { Definitely Not } \\
\text { Prepared }\end{array}$} \\
\hline & & fore & After & Before & After & Before & After & Before & After & Before & After \\
\hline 1. & \begin{tabular}{|l|} 
Duties and \\
Responsibilities \\
of Interns
\end{tabular} & $7(37 \%)$ & $\begin{array}{l}12 \\
(63 \%)\end{array}$ & $8(42 \%)$ & $6(32 \%)$ & $1(5 \%)$ & $1(5 \%)$ & $3(16 \%)$ & & & \\
\hline 2. & \begin{tabular}{|l|} 
Oral \\
Communication \\
\end{tabular} & $\begin{array}{l}6 \\
(32 \%) \\
\end{array}$ & $\begin{array}{l}9 \\
(47 \%)\end{array}$ & $8(42 \%)$ & $9(47 \%)$ & $3(16 \%)$ & $1(5 \%)$ & $1(5 \%)$ & & $1(5 \%)$ & \\
\hline 3. & $\begin{array}{l}\text { Written } \\
\text { Communication }\end{array}$ & $7(37 \%)$ & $\begin{array}{l}12 \\
(63 \%)\end{array}$ & $9(47 \%)$ & $6(32 \%)$ & $3(16 \%)$ & $2(11 \%)$ & & & & \\
\hline 4. & \begin{tabular}{|l|} 
Maintaining \\
Patients' Records
\end{tabular} & $3(16 \%)$ & $\begin{array}{l}11 \\
(58 \%)\end{array}$ & $9(47 \%)$ & $7(37 \%)$ & $4(21 \%)$ & $2(11 \%)$ & $2(11 \%)$ & & $1(5 \%)$ & \\
\hline 5. & Interns Diary & $8(42 \%)$ & $\begin{array}{l}14 \\
(74 \%)\end{array}$ & $7(37 \%)$ & $5(26 \%)$ & $2(11 \%)$ & & $1(5 \%)$ & & $1(5 \%)$ & \\
\hline 6. & Patient Safety & $3(16 \%)$ & $\begin{array}{l}8 \\
(42 \%)\end{array}$ & $9(47 \%)$ & $9(47 \%)$ & $5(26 \%)$ & $2(11 \%)$ & $1(5 \%)$ & & $1(5 \%)$ & \\
\hline 7. & \begin{tabular}{|l|} 
Rational \\
Diagnostics \& \\
Therapy
\end{tabular} & $3(16 \%)$ & $\begin{array}{l}8 \\
(42 \%)\end{array}$ & $7(37 \%)$ & $8(42 \%)$ & $5(26 \%)$ & $2(11 \%)$ & $2(11 \%)$ & $1(5 \%)$ & ) $2(11 \%)$ & \\
\hline 8. & Ethics & $4(21 \%)$ & $\begin{array}{l}8 \\
(42 \%)\end{array}$ & $\begin{array}{l}7 \\
(37 \%)\end{array}$ & $6(32 \%)$ & $5(26 \%)$ & 4 & $2(11 \%)$ & $1(5 \%)$ & $1(5 \%)$ & \\
\hline 9. & Professionalism & $2(11 \%)$ & $\begin{array}{l}7 \\
(37 \%)\end{array}$ & $5(26 \%)$ & $\begin{array}{l}10 \\
(53 \%)\end{array}$ & $6(32 \%)$ & 1 & $4(21 \%)$ & $1(5 \%)$ & ) $2(11 \%)$ & \\
\hline 10. & $\begin{array}{l}\text { Medico-legal } \\
\text { Aspects }\end{array}$ & $2(11 \%)$ & $\begin{array}{l}6 \\
(32 \%)\end{array}$ & $4(21 \%)$ & $\begin{array}{l}10 \\
(53 \%)\end{array}$ & $7(37 \%)$ & $2(11 \%)$ & $2(11 \%)$ & $1(5 \%)$ & ) $4(21 \%)$ & \\
\hline 11. & Drug Promotion & $1(5 \%)$ & $\begin{array}{l}6 \\
(32 \%)\end{array}$ & $5(26 \%)$ & $9(47 \%)$ & $6(32 \%)$ & 4 & $3(16 \%)$ & & $4(21 \%)$ & \\
\hline 12. & \begin{tabular}{|l} 
Biomedical \\
Waste \\
Management
\end{tabular} & $4(21 \%)$ & $\begin{array}{l}10 \\
(53 \%)\end{array}$ & $6(32 \%)$ & $9(47 \%)$ & $5(26 \%)$ & & $2(11 \%)$ & & $2(11 \%)$ & \\
\hline
\end{tabular}

Table-2. Showing the individual raw score and the level of preparedness of the interns before and after the orientation programme.

\begin{tabular}{|c|c|c|c|c|c|c|}
\hline \multirow[t]{2}{*}{ Candidate } & \multicolumn{3}{|c|}{ Before Orientation Programme } & \multicolumn{3}{|c|}{ After Orientation Programme } \\
\hline & Total Raw Score & $\%$ & $\begin{array}{l}\text { Level } \\
\text { of Preparedness }\end{array}$ & $\begin{array}{l}\text { Total } \\
\text { Raw Score }\end{array}$ & $\%$ & $\begin{array}{l}\text { Level } \\
\text { of Preparedness }\end{array}$ \\
\hline 1 & 26 & 54 & Moderate & 39 & 81 & High \\
\hline 2 & 36 & 75 & High & 48 & 100 & High \\
\hline 3 & 35 & 73 & High & 44 & 92 & High \\
\hline 4 & 21 & 44 & Low & 37 & 77 & High \\
\hline 5 & 28 & 58 & Moderate & 44 & 92 & High \\
\hline 6 & 37 & 77 & High & 42 & 88 & High \\
\hline 7 & 36 & 75 & High & 36 & 75 & High \\
\hline 8 & 30 & 63 & Moderate & 48 & 100 & High \\
\hline 9 & 42 & 88 & High & 48 & 100 & High \\
\hline 10 & 32 & 67 & Moderate & 36 & 75 & High \\
\hline 11 & 33 & 69 & Moderate & 36 & 75 & High \\
\hline 12 & 37 & 77 & High & 46 & 96 & High \\
\hline 13 & 29 & 60 & Moderate & 30 & 63 & Moderate \\
\hline 14 & 28 & 58 & Moderate & 48 & 100 & High \\
\hline 15 & 29 & 60 & Moderate & 48 & 100 & High \\
\hline 16 & 29 & 60 & Moderate & 36 & 75 & High \\
\hline 17 & 29 & 60 & Moderate & 48 & 100 & High \\
\hline 18 & 25 & 52 & Moderate & 48 & 100 & High \\
\hline 19 & 21 & 43 & Low & 46 & 96 & High \\
\hline
\end{tabular}


The group mean raw score of preparedness toward internship before the interns orientation programme was 30.68. After the orientation programme the group mean raw score of preparedness towards internship increased significantly to 42.53 which was statistically significant $(\mathrm{P}<0.001)$. With respect to the level of preparedness before internship $2(11 \%)$ had low, $11(58 \%)$ had moderate and $6(32 \%)$ had high level of preparedness. The level of preparedness after the orientation programme was found to be moderate with $1(5 \%)$ intern and high with 18 (95\%) interns (Table 2).

\subsection{Suggestions from the Interns on New Topics for the Orientation Programme}

The interns expressed their desire to learn new topics like giving and receiving effective feedback, interpersonal skills, stress management, time management, dealing with disruptive patients, problem solving skills, clinical skills, guidance to prepare for postgraduate entrance exams and available job avenues.

\subsection{Other Suggestions/Comments from the Interns}

Other suggestions and comments expressed by the interns were; periodic refresher course at least once in a month to review progress in knowledge and skills and they want to know how the internship programme will be evaluated at the end of internship for certification.

\section{Discussion}

High profile studies have recorded concerns about the transition from student to doctor as abrupt and stressful, and it affects their learning of different skills and develop confidence to practice medicine (Committee of Deans of Australian Medical Schools: DEST Medical Education Study, 2006; Berridge et al., 2007; Kilminster et al., 2011). The findings of the present study revealed an overall improvement in the preparedness of interns towards internship after attending the orientation programme. These findings are in agreement with the study conducted to evaluate a new 'Preparation for Internship' course, which was developed to facilitate the transition of University of New South Wales medical graduates from Medical School to Internship (Scicluna et al., 2014). The improved raw scores after attending the orientation programme indicates increased confidence following the programme, and the programme's contents directly mitigated some fears. This study is a self-reporting by interns and self-reporting of preparedness will help the medical educators to predict professional behaviours of interns and therefore it is a valid approach (Aretz, 2003; Bingham and Crampton, 2011; Muthaura et al., 2015).

The interns' interest in this study to learn new topics as part of orientation programme and their other suggestions and comments indicates their positive attitude towards internship and this orientation programme has oriented them to identify these relevant areas. Overall, this orientation programme was well received and experienced by the interns in its present condition which places explicit emphasis on generic capabilities needed for professional practice of medicine during internship. This also indicates that the tertiary teaching hospital where this study was conducted is adequately preparing their interns for their role as interns. Such programmes will help medical institutions to adequately prepare their students for their role as interns. Similar programmes can also be made mandatory to scaffold medical graduates' transition to internship (Cave et al., 2009). Studies like this will also help to uncover deficiencies in educational opportunities for interns and draw the attention of medical educators for needful policy measures and relevant educational interventions (Berridge et al., 2007).

\section{Conclusion}

The preparation of graduates for the transition to internship is the primary responsibility of medical schools. This programme to support the transition from medical student to practicing doctor was useful and effective, but could be improved by including emerging areas of internship training and by increasing the number of training days. This pilot study may also be conducted at a large scale among more number of interns and continuously over a period of years. Making such programmes more effective is of paramount importance for preparing medical graduates well for their transition to become medical officers and subsequently professionalism and patient safety are assured.

\section{References}

Aretz, H.T., 2003. How good is the newly graduated doctor and can we measure it? Medical Journal of Australia, 178(4): 147-147. View at Google Scholar

Berridge, E.J., D. Freeth, J. Sharpe and C.M. Roberts, 2007. Bridging the gap: Supporting the transition from medical student to practising doctor - a two-week preparation programme after graduation. Medical Teacher, 29(2-3): 119-127. View at Google Scholar $\mid$ View at Publisher

Bingham, C.M. and R. Crampton, 2011. A review of prevocational medical trainee assessment in New South Wales. Medical Journal of Australia, 195(7): 410-412. View at Google Scholar | View at Publisher

Brennan, N.I., O. Corrigan, J. Allard, J. Archer, R. Barnes, A. Bleakley, T. Collett and S.R. De Bere, 2010. The transition from medical student to junior doctor: Today's experiences of tomorrow's doctors. Medical Education, 44(5): 449-458. View at Google Scholar | View at Publisher

Cave, J., K. Woolf, A. Jones and J. Dacre, 2009. Easing the transition from student to doctor: How can medical schools help prepare their graduates for starting work? Medical Teacher, $31(5)$ : 403-408. View at Google Scholar | View at Publisher

Committee of Deans of Australian Medical Schools: DEST Medical Education Study, 2006. Sydney: University of Sydney.

Gome, J.J., D. Paltridge and W.J. Inder, 2008. Review of intern preparedness and education experiences in general medicine. Internal Medicine Journal, 38(4): 249-253. View at Google Scholar | View at Publisher

Gouda, P., K. Kitt, D.S. Evans, D. Goggin, D. McGrath, J. Last, M. Hennessy, R. Arnett, S. O'Flynn, F. Dunne and D. O'Donovan, 2016. Irish medical students understanding of the intern year. Irish Medical Journal, 109(4): 387. View at Google Scholar

Guidelines on Remediation of Doctors in the Intern Year, 2012. Retrieved from https://www.medicalcouncil.ie/Education/Career-StageIntern/Quality-Assurance/Guidelines-on-Remediation-of-Doctors-in-the-Intern-Year.pdf.

Kilminster, S.M., M. Zukas, N. Quinton and T. Roberts, 2011. Preparedness is not enough: Understanding transitions as critically intensive learning periods. Medical Education, 45(10): 1006-1015. View at Google Scholar | View at Publisher

McNeil, H.P., H.A. Scicluna, P. Boyle, M.C. Grimm, K.A. Gibson and P.D. Jones, 2012. Successful development of generic capabilities in an undergraduate medical education program. Higher Education Research and Development, 31(4): 525-539. View at Google Scholar | View at Publisher

Medical Council of India Regulations on Graduate Medical Education, 1997. New Delhi: Medical Council of India. 
Muthaura, P.N., T. Khamis, M. Ahmed and S.R. Hussain, 2015. Perceptions of the preparedness of medical graduates for internship responsibilities in district hospitals in Kenya: A qualitative study. BMC Medical Education, 15(1): 178-189. View at Google Scholar | View

Scicluna, H.A., M.C. Grimm, P.D. Jones, L.S. Pilotto and H.P. McNeil, 2014. Improving the transition from medical school to internship evaluation of a preparation for internship course. BMC Medical Education, 14(1): 23-29. View at Google Scholar | View at Publisher 